\title{
Evidence for a Hemibiotrophic Association of the Pitch Canker Pathogen Fusarium circinatum with Pinus radiata
}

Cassandra L. Swett, Department of Plant Science and Landscape Architecture, University of Maryland, College Park 20742; and Sharon C. Kirkpatrick and Thomas R. Gordon, Department of Plant Pathology, University of California, Davis 95616

\begin{abstract}
Swett, C. L., Kirkpatrick, S. C., and Gordon, T. R. 2016. Evidence for a hemibiotrophic association of the pitch canker pathogen Fusarium circinatum with Pinus radiata. Plant Dis. 100:79-84.

Fusarium circinatum can be a cause of mortality in pine seedlings but it is also possible for infected seedlings to remain symptomless. The results of this study documented a biotrophic phase in symptomless Pinus radiata seedlings that can persist for at least 52 weeks. A strain of $F$. circinatum, transformed to express the green fluorescent protein, was observed to grow intercellularly in the root cortex, with no evidence of damage to surrounding cells. Under experimental conditions, shoot symptoms developed only following collar infection, and root deterioration was seen only in plants that first expressed aboveground symptoms. This sequence of events implies that damage to the root

system was a secondary consequence of girdling. If so, root symptoms may not reliably detect seedlings infected by $F$. circinatum. Supplemental mineral nutrition increased the incidence of infection and symptom development in seedlings but some infected plants remained symptomless, precluding the use of this approach to detect infected seedlings. Overall, our findings suggest that the ecological activities of $F$. circinatum may not be limited to a necrotrophic association with pine trees. A more comprehensive understanding of the life history of this fungus may yield insights that contribute to more effective management of pitch canker.
\end{abstract}

Pitch canker, caused by the fungus Fusarium circinatum Nirenberg \& O'Donnell (=F. subglutinans f. sp. pini), affects pine species in plantations, seed orchards, and nurseries throughout the world (Wingfield et al. 2008). In California, pitch canker occurs in both landscape trees and native forests, where it is damaging to Pinus radiata D. Don, $P$. muricata, and $P$. attenuata (Gordon 2013). Canopy dieback is a common symptom of pitch canker that results from a girdling lesion in succulent or recently lignified tissue proximal to the branch tip. Over time, coalescing lesions can girdle larger branches, and infections on the main stem can be a cause of tree mortality (Dwinell et al. 1985).

F. circinatum also infects seedlings as a result of exposure to inoculum carried on seed or in soil. Emergent seedlings may die quickly following infection, and mortality caused by $F$. circinatum results in major nursery seedling losses in South Africa (Viljoen et al. 1994) and elsewhere in the world (Wingfield et al. 2008). Roots that are visibly damaged by $F$. circinatum can be extensively colonized, with growth extending into the vascular tissue (Martín-Rodrigues et al. 2015). It is also possible for seedlings to sustain infections that do not result in aboveground symptoms (Storer et al. 1998; Swett and Gordon 2011, 2012). In commercial production, cryptically infected seedlings are prone to failure following outplanting in plantations, possibly due to stress-induced activation of latent infections (Mitchell et al. 2004, 2011; Morris 2010). Cryptic infections may also provide a means of regional spread as well as foreign introductions through movement of plants in the nursery trade (Gordon 2011).

When inoculated into pine branches through a wound, growth of $F$. circinatum is associated with rapid death of host tissue and, consequently, the pathogen is regarded as a necrotroph. A similar mode of growth in roots would be consistent with the observed lethal effects of $F$. circinatum on seedlings. Based on this expectation, visual inspection of the root system has been employed as a means of identifying infections in seedlings without aboveground symptoms

Corresponding author: T. R. Gordon; E-mail: trgordon@ucdavis.edu

Accepted for publication 19 May 2015.

http://dx.doi.org/10.1094/PDIS-03-15-0270-RE

(C) 2016 The American Phytopathological Society
(Gordon 2011; Morris 2010). However, the nature of the association between $F$. circinatum and pine roots has not been well characterized, and it is not known if the fungus is strictly necrotrophic in roots or if it has a biotrophic phase that precedes visible damage associated with seedling decline and death (Storer et al. 1998). To gain a better understanding of the manner in which $F$. circinatum interacts with pine seedlings, the present study was undertaken to examine root colonization histologically, characterize the condition of roots that are colonized by the fungus, and document the sequence of events leading to development of symptoms above- and belowground. In addition, because previous work has shown that nitrogen $(\mathrm{N})$ can influence development of pitch canker in plantations (Lopez-Zamora et al. 2007), we tested the effect of mineral nutrition on symptom induction to determine whether supplemental nutrients could reveal the presence of the pathogen in cryptically infected seedlings.

\section{Materials and Methods}

Plant material. All tests used the P. radiata seed line GF 16 (halfsibs), obtained from a New Zealand distributor (Proseed, Amberley, North Canterbury, NZ). In preparation for planting, seed were immersed for $30 \mathrm{~s}$ in $70 \% \mathrm{ETOH}$ followed by $2 \mathrm{~min}$ in $1.0 \% \mathrm{NaClO}$, rinsed in sterile water, then soaked in sterile water overnight. Plants were grown in 60-weight Monterey beach sand (Lapis Lustre Natural Monterey beach sand; CEMEX), which was autoclaved twice for $1 \mathrm{~h}$, approximately $24 \mathrm{~h}$ apart. Seed were planted at a depth of approximately $2 \mathrm{~cm}$ in Ray Leach Cone-tainers $(21$ by $3.8 \mathrm{~cm}, 164 \mathrm{ml}$; Steuwe and Sons, Tangent, OR) and maintained in a greenhouse wherein temperatures ranged from 27 to $37^{\circ} \mathrm{C}$. Irrigation with deionized water was supplied by misters for the first 4 weeks. Thereafter, seedlings were supplied with tap water as needed.

Histological analysis. Tissue colonization was examined using epifluorescent microscopy to visualize a green fluorescent protein (GFP)-expressing strain of F. circinatum (GL17-GH7). Transformation was accomplished using the protocol described by Covert et al. (2001). The transformed isolate was originally recovered from a lesion on $P$. radiata in Monterey, CA. Pine seedlings grown in sterilized sand in a greenhouse were gently uplifted 5 to 7 days after emergence and roots were rinsed under deionized water to remove residual sand. Thereafter, plant roots were immersed in a spore suspension for $1 \mathrm{~min}$. Seedlings that served as negative (noninoculated) controls were treated in the same manner but were immersed in $0.5 \%$ 
$\mathrm{KCl}$ in sterile, deionized water instead of a spore suspension. To prepare inoculum, spores and mycelium of 5- to 7-day-old cultures growing on potato dextrose agar were suspended in sterile $0.5 \%$ $\mathrm{KCl}$ and filtered through two layers of cheesecloth. Spore densities were quantified using a hemocytometer and adjusted to $1 \times 10^{7}$ spores $/ \mathrm{ml}$ by the addition of sterile $0.5 \% \mathrm{KCl}$. Spore suspensions were stored at $4{ }^{\circ} \mathrm{C}$ and used within $24 \mathrm{~h}$ of preparation. Spore viability was evaluated by inoculating Fusarium selective medium (FSM) with dilutions of each suspension, as described by Aegerter and Gordon (2006). It was thereby determined that seedlings were inoculated with a mean of $9.05 \pm 0.15 \times 10^{6}$ viable spores $/ \mathrm{ml}$ across all experiments.

Inoculated plants were maintained in moist incubation chambers at room temperature $\left(23\right.$ to $\left.26^{\circ} \mathrm{C}\right)$ under ambient lighting, and observed microscopically between 2 and 9 days postinoculation. Roots with a firm, white appearance were aseptically excised from plants with healthy-looking shoots. To examine surface colonization, intact roots were viewed directly. Internal colonization was examined in longitudinal sections by aseptically removing the epidermal layer on two opposing sides of the root, and in cross sections that were prepared by hand with a razor blade.

Inoculated roots were observed with an Axio Imager.M2 epifluorescent microscope (Zeiss, Oberkochen, Germany), with a $\times 10$ objective (EC Plan-NEOFLUAR $\times 10 / 0.25$; Zeiss), $\times 20$ objective (EC Plan-NEOFLUAR $\times 20 / 0.5$; Zeiss), and a $\times 40$ objective (EC PlanNEOFLUAR $\times 40 / 0.75$; Zeiss). A GFP filter cube (exciter: 470/40; emitter: 525/50; beamsplitter 495) was used to examine colonized roots, together with a rhodamine cube (exciter: 546/12; emitter: 607/80; beamsplitter: 560) to detect autofluorescence from the root, and phase contrast to examine root cells. Macros created with the program Axiovision (version 4.8; Zeiss) served to automate image analysis. Z stacks were used to capture colonization events across 12 - to $70-\mu \mathrm{m}$ depths, taken as 2 - to $7-\mu \mathrm{m}$ slices with 6 to 14 slices per stack. Stacks were compressed using the wavelets algorithm to create a single image.

Symptom development and colonization patterns. To obtain infected seedlings, seeds were sown within a 5-cm layer of autoclaved sand, below which was either a 7-cm layer of sand infested with a known virulent isolate of $F$. circinatum (GL 290) or noninfested sand for control (noninfected) seedlings. Infestations were established by adding spore suspensions, prepared as described above, to autoclaved sand, which was thereafter air dried for $24 \mathrm{~h}$ at room temperature $\left(24\right.$ to $\left.27^{\circ} \mathrm{C}\right)$. Aqueous suspensions of infested sand were spread over the surface of FSM plates and colonies of F. circinatum were enumerated 5 to 7 days later. On this basis, inoculated sand was determined to have an average of 3,200 \pm 240 viable spores/g at the time of planting across both experiments. Plants were supplied with tap water as needed and were not fertilized. Seedlings were examined 4 to 6 weeks after emergence and the study was repeated.

For an assessment of plant condition and colonization by F. circinatum, seedlings were selected to represent each of the following categories: (i) minor shoot symptoms (7 to 10 plants), (ii) severe shoot symptoms (7 to 10 plants), and (iii) asymptomatic shoot (14 to 20 plants, double the number of plants in each symptomatic plant category). Seedlings in the "asymptomatic shoot" category were grown in infested sand and had healthy-looking shoot tissue. Plants in the "minor shoot symptoms" category were grown in infested sand and had symptoms only in the cotyledonary needles (chlorosis, minor needle browning). The category "severe shoot symptoms" applied to seedlings grown in infested sand with chlorosis or browning of cotyledonary and primary needles, as well as loss of turgidity in some cases. Asymptomatic plants grown in noninfested, autoclaved sand served as negative controls ( 7 to 10 plants). Sample sizes were based on the maximum number of symptomatic plants obtainable and, in the case of asymptomatic plants grown in infested sand, this number was doubled because it could not be determined at the time of harvest whether or not symptomless plants were infected.

Plants were gently removed from soil and their roots were rinsed in sterile, deionized water and placed on moist paper towels. Tap root condition was rated on a 1-to-7 scale, as follows: $1=$ all roots white or up to $10 \% \tan$ in color; $2=>10 \%$ of roots tan, $<10 \%$ dark brown; $3=10$ to $50 \%$ of roots dark brown; $4=51$ to $70 \%$ of roots dark brown; $5=$ as in 4 , with vascular detachment in 10 to $20 \%$ of roots; $6=71$ to $100 \%$ of roots dark brown to black and vascular detachment in 20 to $50 \%$ of roots; and 7 = vascular detachment in $100 \%$ of the root system. An assessment that included feeder roots was also conducted but categorization on that basis matched tap root condition ratings (data not shown); therefore, only the latter are presented. After evaluation of root condition, plants were blotted with paper towels to remove residual moisture, and total root and shoot tissues were weighed separately.

Following rating and biomass assays, plants were stored at $4{ }^{\circ} \mathrm{C}$ for up to 4 days. To prepare samples for isolations, the whole root system and the de-needled stem were washed in tap water with $0.1 \%$ Tween 20 , dipped in $70 \%$ ETOH for $30 \mathrm{~s}$, and immersed for $2 \mathrm{~min}$ in $0.1 \%$ $\mathrm{NaOCl}$. Stem tissue was separated into (i) the collar, comprising the total subterranean stem (below the soil line but above the point at which lateral roots emerged) plus $1 \mathrm{~cm}$ of the aboveground stem, and (ii) the stem above the collar, both of which were cut into sections approximately $1 \mathrm{~cm}$ in length and placed on plates of FSM. All root tissue was cut into 5-cm sections and placed on FSM. Plates were incubated at 24 to $26^{\circ} \mathrm{C}$ under ambient lighting for 7 days. Cultures were identified as $F$. circinatum based on colony morphology on FSM and, when necessary, microscopic characteristics on water agar amended with $0.6 \% \mathrm{KCL}$, using the criteria described by Leslie et al. (2006). The incidence of infection was quantified as the percentage of assayed plants with at least one infected tissue segment (root, collar, or shoot). Conditional intensity (extent) of stem colonization corresponded to the percentage of $1-\mathrm{cm}$ segments that were infected, for colonized plants only. The conditional intensity of root colonization corresponded to the number of distinct colonies per unit root length for colonized plants only. By excluding noninfected plants from the calculation, conditional intensity provides a measure of the extent to which successful infections result in exploitation of host tissue, similar to the measure of conditional disease severity described by McRoberts et al. (2003).

Persistence of symptomless infections. To establish root infections, seedlings were germinated in stratified, infested sand as described above, using a known pathogenic isolate of $F$. circinatum (GL 17), or in pathogen-free sand (noninoculated treatment). Based on assays of spore viability in infested sand, mean inoculum densities (ID) were $22.5 \pm 12.5$ and $304.5 \pm 45.5$ spores/g for low and high ID, respectively, across both experiments. Plants were watered as needed and were never fertilized. Twelve weeks after seeds were sown, plants were gently removed from pots and, after roots were washed under running water, transplanted into double autoclaved sand in new planting tubes $(21$ by $3.8 \mathrm{~cm}$ ).

Following transplanting, mortality was recorded every 4 weeks for the next 40 weeks. At each assessment, all symptomatic plants were assayed for $F$. circinatum infection by surface disinfesting the stem and the tap root and culturing on FSM, as described above. At 1 year postplanting, root and shoot fresh weights were recorded for all surviving plants, together with an equal number of control plants (grown in noninfested sand). Colonization was assayed in all inoculated plants plus eight control plants by surface disinfesting the stem and the tap root and culturing on FSM, as described above. The experiment was conducted twice.

Effect of nutrient treatment on infection and symptom expression. Seeds were sown as described above in sand that was either infested with $F$. circinatum isolate GL 290 or noninfested. Plants were maintained in a greenhouse at 24 to $30^{\circ} \mathrm{C}$ and supplied with water as needed. Inoculated plants were arranged in four blocks, with three plants of each treatment per block. Seedlings were not fertilized during the first year but, beginning 1 year after planting, Peters Professional 20:7:19 Conifer Grower was applied to each pot in approximately $10 \mathrm{ml}$ of water at a rate that corresponded to $\mathrm{N}$ at either 25 or $400 \mathrm{ppm}$. Nutrient treatments were applied every other week for 8 weeks (the lower level was selected to avoid effects of $\mathrm{N}$ deficiency). At 6 and 10 months after final nutrient treatment, plants 
were rated as diseased (chlorosis or browning of needles, with or without loss of apical turgidity) or healthy, and isolations were conducted for all plants that developed symptoms, as described above. At 10 months, all roots of the remaining symptomless plants were surface disinfested as described above and placed on FSM, and plants were scored as infected if one or more $F$. circinatum colonies emerged from the root system. This experiment was conducted twice.

Data analysis. Analysis of variance (ANOVA) and Tukey's pairwise means comparison test, as implemented in R 2.12.0, were used to assess treatment effects on disease incidence, colonization intensity, and plant biomass. Percentage data were subjected to an arcsin square-root transformation prior to the analysis. Treatment effects on root condition were analyzed using Proc mixed, as implemented in SAS version 9.1, as described by Shah and Madden (2004). Unless otherwise noted, experiment-treatment interactions were not significant; therefore, data were pooled across experiments to test the significance of main effects.

\section{Results}

Histological analysis of colonization patterns in asymptomatic root tissue. The colonization patterns described were observed in lateral and tap roots of at least three seedlings in each of three independent sets of inoculations. Spore germination and hyphal growth were densest near the root tip but were also observed on distal portions of the root (Fig. 1A). Surface hyphae were predominantly oriented in parallel to the long axis of the root (Fig. 1B). Entry into the root appeared to occur at the junction of plant cell walls. There was no evidence that these infections were associated with wounding, based on the absence of autofluorescence or observable loss of cellular integrity. Within roots, hyphal growth was limited to the apoplast of epidermal (Fig. 1C and D) and cortical (Fig. 1E) tissues, and was primarily unidirectional, oriented in parallel to the long axis of the root. Hyphal growth toward the central core of the root was also observed (Fig. 1F) but it did not extend into the vascular stele (Fig. 1G).

Symptom development and colonization patterns. After infection data were obtained, seedlings in each of the shoot symptom categories (described above) were classified as follows: (i) noninfected, shoot asymptomatic; (ii) infected, shoot asymptomatic; (iii) infected, shoot symptoms minor; and (iv) infected, shoot symptoms severe. For all "infected" categories, only those plants with confirmed infections were included. Consequently, in the case of the infected-asymptomatic group, approximately $50 \%$ of sampled plants were excluded from analyses.

For plants without shoot symptoms, whether infected or not, all roots were firm, with no evidence of degradation, and ranged from white/tan to dark brown in color (root condition rating from 1 to 4 ;

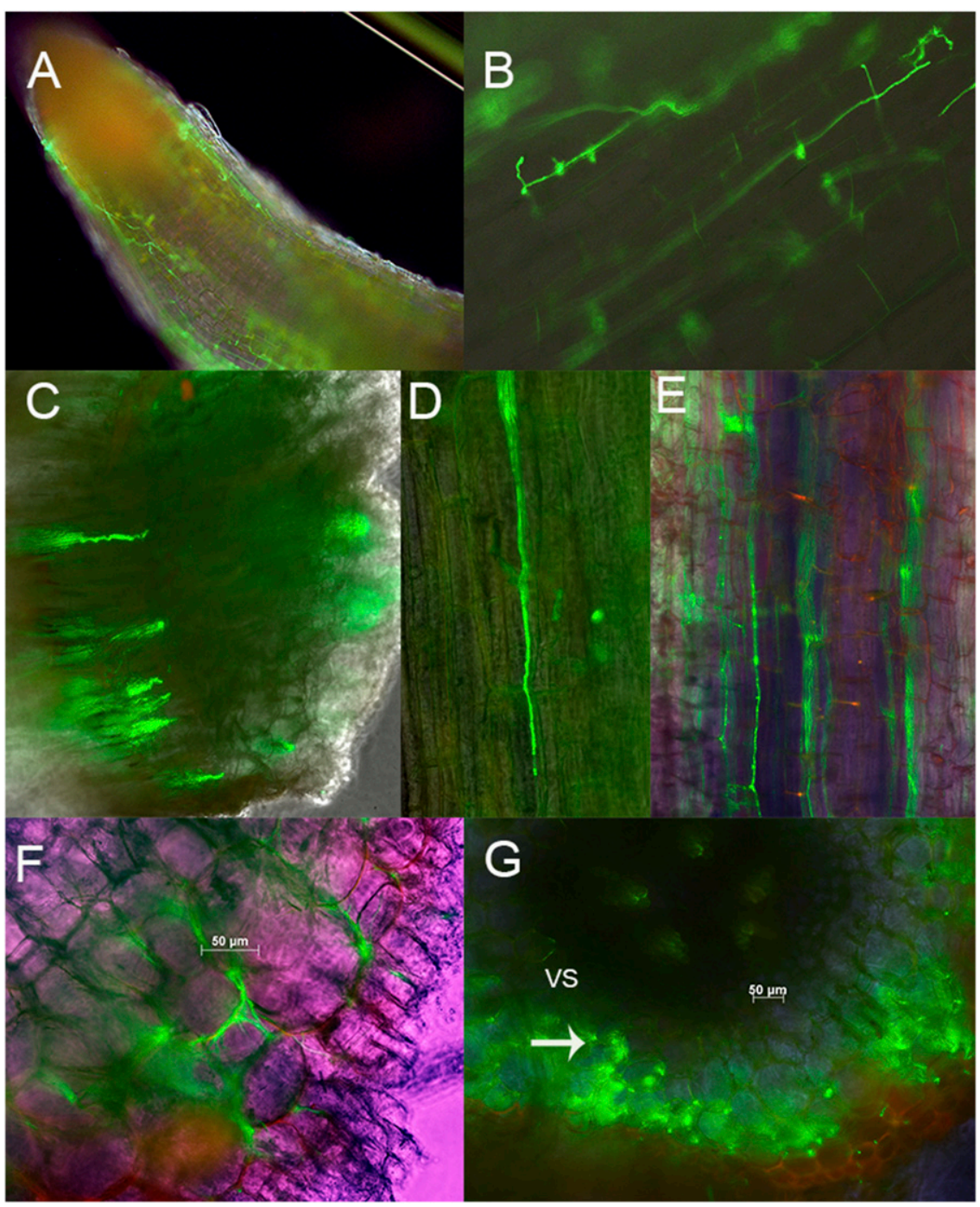

Fig. 1. Pine root tissue colonized by Fusarium circinatum 3 to 6 days post inoculation, showing A, hyphal growth at the root tip; B, spore germination and growth on the root surface; $\mathbf{C}$, unidirectional growth parallel to the long axis of the root in the apoplast of the epidermis of a root in cross section; $\mathbf{D}$, the underside of the epidermis and $\mathbf{E}$, the cortical tissue; F, growth within the apoplast of the cortex; and G, internal colonization of epidermal and cortical tissue in cross section (arrow illustrates that hyphal growth does not penetrate beyond the outer vascular stele [vs]). 
(Fig. 2; Table 1). Accordingly, all roots with a rating $\leq 4$ were considered healthy. Root degradation (severity rating $>4$ ) was evident in $15 \pm 2 \%$ of plants with minor shoot symptoms and $78 \pm 22 \%$ of plants with severe shoot symptoms (Table 1). Shoot condition was a significant source of variation in the percentage of plants with symptomatic roots $(P=0.027)$ and in the extent of damage to a plant's root system, as indicated by ratings of tap root condition $(P<0.001)$. The most extensive damage was observed on plants with severe shoot symptoms, followed by plants with minor shoot symptoms (Table 1).

Shoot condition was a significant source of variation in both root biomass $(P<0.001)$ and shoot biomass $(P<0.001)$. There was not a significant difference in either root or shoot biomass between noninfected and infected plants with asymptomatic shoots $(P>0.05)$ (Table 1). Plants with both minor and severe shoot symptoms had significantly lower root and shoot biomass than asymptomatic plants that were either infected or noninfected $(P<0.05)$ (Table 1).
To further characterize the association of symptoms with colonization by $F$. circinatum, infected plants were placed in one of three condition categories: (i) asymptomatic, (ii) shoot symptoms only, or (iii) symptoms in both shoot and root tissue. The results of ANOVA indicated that plant condition was a significant source of variation in the incidence of collar infection $(P=0.04)$, reflecting a lower incidence in asymptomatic plants than in plants with both shoot and root symptoms (Table 2). The incidence of stem infection was lower in asymptomatic than in symptomatic plants but the difference was not significant $(P=0.08)$. On the other hand, plant condition was a significant source of variation in the conditional intensity of stem colonization $(P<0.001)$. Only $3.5 \pm 2 \%$ of segments were colonized in asymptomatic plants, compared with $30 \pm 10 \%$ of segments in plants with only shoot symptoms and $67 \pm 8 \%$ in plants with both shoot and root symptoms (Table 2).

The incidence of root colonization was $100 \%$ in all three categories (Table 2) but plant condition was a significant source of variation
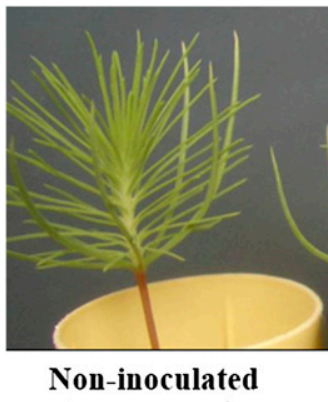

Asymptomatic shoot

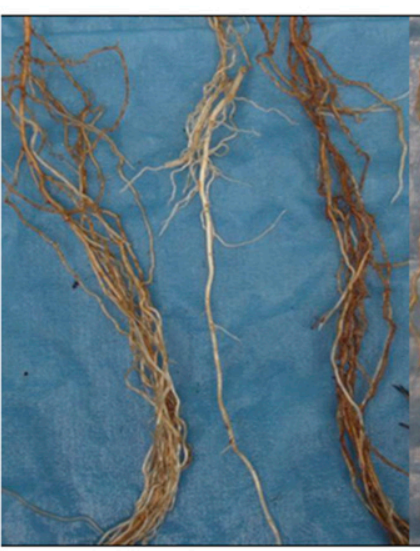

Non-inoculated

Asymptomatic root system

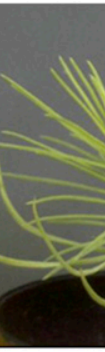

Inoculated

Asymptomatic shoot

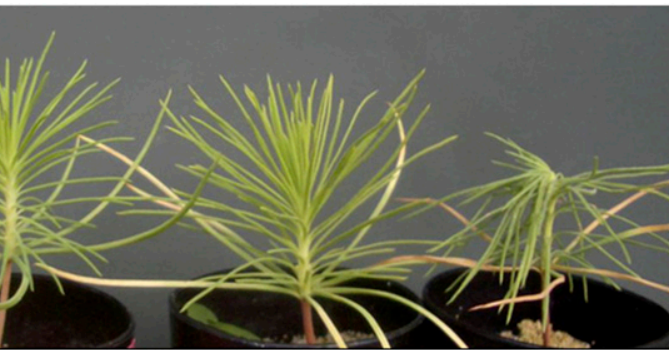

Inoculated Cotyledonary symptoms only
Inoculated

Primary needle

symptoms

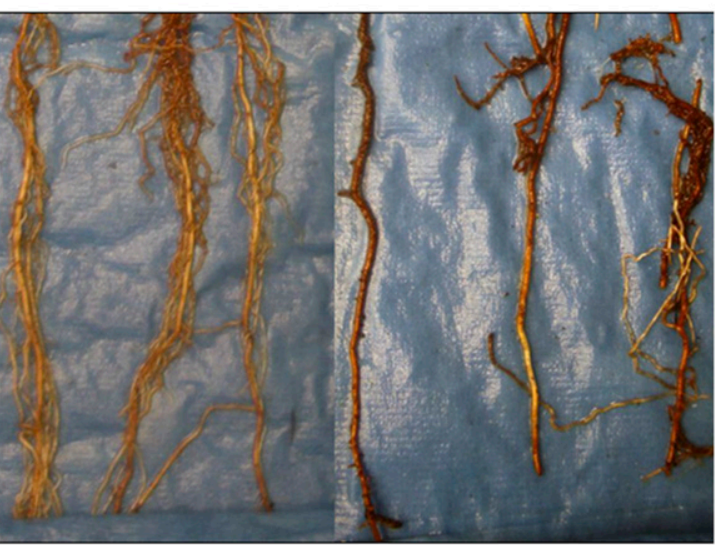

Inoculated

Inoculated

Asymptomatic root system

Fig. 2. Shoot (top) and root (bottom) condition 8 to 10 weeks after planting of seedlings that were either noninoculated and healthy, inoculated but asymptomatic, or inoculated and symptomatic.

Table 1. Root condition and plant biomass of Pinus radiata seedlings grown in sand with or without inoculum of Fusarium circinatum ${ }^{\mathrm{v}}$

\begin{tabular}{|c|c|c|c|c|c|}
\hline Infection category & Shoot symptomsw & Root condition $^{x}$ & Root rot incidence $(\%)^{y}$ & Root biomass $(\mathbf{g})^{\mathrm{z}}$ & Shoot biomass $(\mathrm{g})^{\mathrm{z}}$ \\
\hline Not infected & Asymptomatic & $1.76 \pm 0.18 \mathrm{a}$ & $0 \mathrm{a}$ & $0.57 \pm 0.04 \mathrm{a}$ & $0.41 \pm 0.03 \mathrm{a}$ \\
\hline Infected & Asymptomatic & $2.22 \pm 0.18 \mathrm{a}$ & $0 \mathrm{a}$ & $0.53 \pm 0.03 \mathrm{a}$ & $0.43 \pm 0.04 \mathrm{a}$ \\
\hline Infected & Minor & $3.28 \pm 0.33 b$ & $15 \pm 2 \mathrm{ab}$ & $0.33 \pm 0.03 b$ & $0.28 \pm 0.02 b$ \\
\hline Infected & Severe & $4.94 \pm 0.37 \mathrm{c}$ & $78 \pm 22 b$ & $0.29 \pm 0.02 b$ & $0.19 \pm 0.01 b$ \\
\hline
\end{tabular}

${ }^{v}$ Means ( \pm standard error) followed by different letters are significantly different based on Tukey's pairwise comparison $(P<0.05)$.

${ }^{w}$ Extent of aboveground symptom development.

$\times$ Tap root condition, based on a scale from 1 to 7 , where $1=$ all roots white or up to $10 \%$ tan; $2=>10 \%$ of roots $\tan ,<10 \%$ dark brown; $3=10$ to $50 \%$ of tissue dark brown; $4=51$ to $70 \%$ of tissue dark brown; $5=$ as in 4 , with vascular detachment in 10 to $20 \%$ of tissue; $6=71$ to $100 \%$ of tissue dark brown to black and vascular detachment in 20 to $50 \%$ of tissue; and $7=$ vascular detachment in $100 \%$ of tissue.

y Percentage of plants with symptomatic roots (rating $>4$ ).

${ }^{\mathrm{z}}$ Fresh weight. 
in the conditional intensity of root colonization $(P<0.001)$, based on the number of colonies per meter of root (Table 2 ). This reflected less extensive root colonization in asymptomatic plants than in plants with only shoot symptoms which, in turn, were less extensively colonized than plants with both root and shoot symptoms (Table 2). Thus, when the fungus is restricted to the root system, not only are both the shoot and roots usually asymptomatic (as described above) but fungal growth is constrained as well.

Persistence of symptomless infections. By the end of the study (52 weeks after planting), more seedlings developed symptoms at the high ID $(57 \pm 11 \%)$ than at the low ID $(25 \pm 1 \%)$ and ANOVA showed the effect of ID to be significant $(P=0.006)$. No seedlings in the control group developed symptoms during the observation period. Based on isolations at the end of the study, a higher percentage of surviving plants were infected at the low ID $(30 \pm 16 \%)$ than at the high ID $(20 \pm 3 \%)$ (Table 3$)$ but this difference was not significant $(P=0.21)$. At the end of the study, $F$. circinatum was recovered from one of eight plants in the control group in both experiments, indicating a low level of contamination.

The effect of treatment (high ID, low ID, or no inoculum) on shoot fresh weight was significant $(P<0.001)$, reflecting lower mean shoot weight of seedlings at the high ID $(4.6 \pm 0.25 \mathrm{~g} / \mathrm{plant})$ compared with both the low ID $(5.6 \pm 0.18 \mathrm{~g} / \mathrm{plant})$ and noninfested treatments $(5.8 \pm$ $0.25 \mathrm{~g} /$ plant). There was not a significant effect of treatment on root fresh weight, which ranged from $3.9 \pm 0.29$ to $4.1 \pm 0.24 \mathrm{~g} /$ plant across all treatments $(P=0.90)$.

Effect of nutrient treatments on disease expression. Six months after the final nutrient application, significantly more seedlings developed shoot symptoms if treated with $\mathrm{N}$ at 400 rather than 25 $\operatorname{ppm}(P=0.001)$ (Table 4). ANOVA indicated a significant experimenttreatment interaction for disease incidence at 10 months $(P=$ $0.007)$, due to differences in symptom development in the 25-ppm treatment; therefore, data for the two experiments were analyzed separately. The treatment effect on incidence of symptomatic plants was

Table 2. Incidence of infection and extent of colonization of Pinus radiata seedlings grown in sand infested with Fusarium circinatum $^{\mathrm{w}}$

\begin{tabular}{|c|c|c|c|c|c|}
\hline \multirow{2}{*}{$\begin{array}{l}\text { Symptom } \\
\text { development }\end{array}$} & \multicolumn{3}{|c|}{ Infection incidence $(\%)^{x}$} & \multicolumn{2}{|c|}{$\begin{array}{c}\text { Extent of } \\
\text { colonization }(\%)\end{array}$} \\
\hline & Root & Collar & Stem & $\operatorname{Root}^{\mathbf{y}}$ & Stem $^{\mathbf{z}}$ \\
\hline Asymptomatic & $100 \mathrm{a}$ & $19 \pm 11 \mathrm{a}$ & $14 \pm 6 a$ & $8.5 \pm 2.1 \mathrm{a}$ & $3.5 \pm 2 \mathrm{a}$ \\
\hline $\begin{array}{l}\text { Shoot symptoms } \\
\text { only }\end{array}$ & $100 \mathrm{a}$ & $77 \pm 4 a b$ & $48 \pm 12 \mathrm{a}$ & $59.9 \pm 8.5 \mathrm{~b}$ & $30 \pm 10 b$ \\
\hline $\begin{array}{l}\text { Shoot and root } \\
\text { symptoms }\end{array}$ & $100 \mathrm{a}$ & $93 \pm 7 b$ & $86 \pm 15 \mathrm{a}$ & $80.5 \pm 7.0 \mathrm{c}$ & $67 \pm 8 c$ \\
\hline
\end{tabular}

${ }^{w}$ Means ( \pm standard error) in the same column followed by different letters are significantly different based on Tukey's pairwise comparison $(P<$ $0.05)$.

${ }^{x}$ Percentage of plants infected in each tissue type.

y Extent of colonization (= conditional intensity) based on the number of colonies per meter of root length.

${ }^{z}$ Percentage of $1-\mathrm{cm}$ shoot segments infected.

Table 3. Incidence of disease and symptomless infection in Pinus radiata seedlings 52 weeks after planting in sand infested with Fusarium circinatum

\begin{tabular}{lcc}
\hline Treatment $^{\mathbf{x}}$ & Asymptomatic infection (\%) $^{\mathbf{y}}$ & Disease incidence (\%) $^{\mathbf{z}}$ \\
\hline High ID & $20 \pm 3 \mathrm{a}$ & $57 \pm 11 \mathrm{a}$ \\
Low ID & $30 \pm 16 \mathrm{a}$ & $25 \pm 1 \mathrm{~b}$ \\
\hline
\end{tabular}

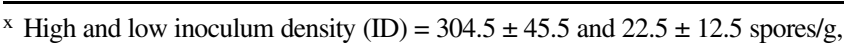
respectively, across two experiments.

y Percentage of asymptomatic plants infected at the end of the experiment. Means ( \pm standard error [SE]) followed by the same letter are not significantly different $(P>0.05)$ based on Tukey's pairwise comparison.

${ }^{\mathrm{z}}$ Percentage of plants that developed disease symptoms (and were confirmed to be infected by $F$. circinatum) by the end of the experiment. Means $( \pm \mathrm{SE})$ followed by different letters are significantly different based on Tukey's pairwise comparison $(P<0.05)$ not significant in experiment one $(P=0.850)$ but was highly significant in experiment two $(P=0.0004)$. Considering both symptomless and symptomatic seedlings together, those treated with $\mathrm{N}$ at $400 \mathrm{ppm}$ had a significantly higher incidence of infection than seedlings treated with $\mathrm{N}$ at $25 \mathrm{ppm}(P=0.028)$ in experiment two. The incidence of infection in asymptomatic plants was somewhat higher in the 400ppm treatment (Table 4) but the difference was not significant $(P>0.05)$.

\section{Discussion}

Overall, the results of this study suggest that $F$. circinatum is not strictly a necrotroph but can also exploit pine hosts without causing visible damage. Our findings show that $F$. circinatum can colonize roots of $P$. radiata seedlings without inducing symptoms either above or below ground, and that colonized plants can remain symptomless for up to 52 weeks from initial exposure to the pathogen. Hyphae can penetrate healthy seedling roots and grow within the apoplast of epidermal and cortical tissue without causing apparent cellular damage. In intercellular spaces, growth is typically unidirectional along the long axis of the root, with occasional branching, which is consistent with exploratory growth in a low nutrient environment (Griffin 1994).

There was no indication of invasive growth into root cells or entry into the vascular stele; as long as infections were confined to roots, plants remained symptomless. Symptom development was strongly associated with colonization of the root collar. Decline of the shoot was followed by extensive colonization and deterioration of the root system. Root deterioration was not seen in plants in the absence of aboveground symptoms and was rarely observed in plants at early stages of shoot decline, only becoming common after primary needle symptoms developed (typically within a week of cotyledonary needle chlorosis).

This sequence implies that infected plants can tolerate growth of $F$. circinatum in roots until the fungus reaches the collar, at which point girdling results in deterioration of both shoot and root tissue. Thereafter, the fungus grows more extensively in the root system, presumably benefitting from greater nutrient availability in dead and dying tissue. This interpretation is consistent with the concept of $F$. circinatum as a seedling pathogen but runs counter to the view that root rot per se is the cause of death. If, as our findings suggest, damage to the root system is typically a secondary consequence of pathogen activity and not an early indication of infection, surveys that rely on root symptoms for detection of $F$. circinatum may not be reliable.

Table 4. Incidence of disease and infection of Pinus radiata seedlings subjected to high and low nutrient treatments

\begin{tabular}{|c|c|c|c|c|c|}
\hline \multirow[b]{3}{*}{ Treatment $^{\mathrm{z}}$} & \multicolumn{3}{|c|}{ Shoot symptom incidence $(\%)^{\mathrm{v}}$} & & \\
\hline & \multirow{2}{*}{$\frac{6 \text { Months }^{w}}{\text { Combined }}$} & \multicolumn{2}{|c|}{10 Months $^{x}$} & \multicolumn{2}{|c|}{ Infection incidence $(\%)^{\mathrm{y}}$} \\
\hline & & Exp. 1 & Exp. 2 & All plants & Symptomless \\
\hline $\begin{array}{l}\mathrm{N} \text { at } 25 \mathrm{ppm} \\
\mathrm{N} \text { at } 400 \mathrm{ppm}\end{array}$ & $\begin{aligned} 8 & \pm 5 \mathrm{a} \\
58 & \pm 10 \mathrm{~b}\end{aligned}$ & $\begin{array}{l}33 \pm 13 a \\
66 \pm 0 a\end{array}$ & $\begin{array}{c}0 \pm 0 \mathrm{a} \\
83 \pm 10 \mathrm{~b}\end{array}$ & $\begin{array}{l}58 \pm 12 \mathrm{a} \\
91 \pm 5 \mathrm{~b}\end{array}$ & $\begin{array}{l}50 \pm 13 a \\
67 \pm 18 a\end{array}$ \\
\hline
\end{tabular}

vercentage of seedlings with disease symptoms at 6 and 10 months after final nutrient treatment. Means ( \pm standard error $[\mathrm{SE}]$ ) in the same column followed by different letters are significantly different based on Tukey's pairwise comparison $(P<0.05)$. F . circinatum was isolated from all symptomatic seedlings.

${ }^{w}$ Data were pooled across both experiments because the experimenttreatment interaction was not significant $(P=0.43)$.

${ }^{\mathrm{x}}$ Experiment-treatment interaction was significant $(P=0.007)$; therefore, data for the two experiments were analyzed separately.

y Percentage of seedlings ( \pm SE) that became infected by the end of the study (10 months after final nutrient treatment) for both experiments combined. Means $( \pm$ SE) in the same column followed by different letters are significantly different based on Tukey's pairwise comparison $(P<0.05)$. All plants $=$ data for symptomless and symptomatic plants combined and Symptomless $=$ symptomless plants only.

${ }^{\mathrm{z}}$ Concentration of nitrogen $(\mathrm{N})$ applied to seedlings in parts per million (ppm). 
Many fungi have the ability to asymptomatically colonize plants. Some of these fungi are obligate biotrophs but many more are hemibiotrophs, capable of growing inside of a plant without inducing symptoms (Stergiopoulos and Gordon 2014) and also, under some circumstances, engaging in more aggressive growth that is damaging to the plant. One well-studied fungus in this category is $F$. verticillioides, which can be both a pathogen and a symptomless endophyte in corn (Bacon and Yates 2006; Kuldau and Yates 2000). F. circinatum is a close relative of $F$. verticillioides and shares the ability to colonize corn (Swett and Gordon 2015) and other grasses (Swett et al. 2014; Swett and Gordon 2012) without inducing symptoms. The results of the present study indicate that this capability may be manifest in pine as well.

Under the conditions of our experiments, $F$. circinatum was commonly associated with asymptomatic roots of pine seedlings, and was also occasionally isolated from asymptomatic shoot tissue. In a separate study, we found that inoculated shoots could become infected without showing symptoms under experimental conditions, and we have recovered $F$. circinatum from symptomless shoots of seedlings in native forests (Swett and Gordon 2014). These findings are unexpected, given that inoculated pine branches are commonly observed to sustain lesions (Gordon 2006). One possible explanation is that necrotrophic growth is conditioned by the wounding that precedes artificial inoculations. If so, it may be that, in nature, shoot infections can occur without wounding, and symptoms follow in response to the damage caused by a wound.

Symptomless seedling infections can play a significant role in development of pitch canker in managed plantings. Cryptically infected seedlings can serve as vehicles for dissemination of the pathogen, and are more likely to die following transplantation into plantations (Mitchell et al. 2011; Morris 2010). Losses associated with cryptic infection could potentially be reduced by selecting for plants with greater resistance to root infections, and development of improved detection methods. Our findings suggest that root infections can be localized, and difficult to detect in a random sampling of symptomless seedlings. In this study, infection and symptom development were both stimulated by an elevated level of nutrients, consistent with previous studies of $\mathrm{N}$-mediated effects on pitch canker development in pine plantations (Lopez-Zamora et al. 2007). If such a treatment induced the expression of disease symptoms in cryptically infected seedlings, without also increasing the incidence of infection, it might be a useful complement to visual surveys for disease. However, our findings do not support the utility of this approach.

Infections of mature $P$. radiata by $F$. circinatum can induce systemic resistance to pitch canker (Bonello et al. 2001; Storer et al. 1999). This appears to have contributed to reduced severity of pitch canker in native $P$. radiata forests (Gordon et al. 2011). If root infections in seedlings have similar effects, they may serve to moderate the impact of disease in young trees, allowing for regeneration under pathogen pressure in native stands.

Overall, the capacity for $F$. circinatum to infect pine seedlings asymptomatically suggests that this fungus may engage in a broader array of ecological activities than has been previously recognized. This possibility, coupled with recognition that $F$. circinatum can infect leaves and stems of grasses (Swett et al. 2014; Swett and Gordon 2012, 2015) suggests that pathogenicity to pine may not be central to the life history of this fungus. Our findings argue for further exploration of the ecological activities of $F$. circinatum, which may lead to insights that can contribute to disease management.

\section{Acknowledgments}

We thank J. Leveau for use of the Zeiss epifluorescent microscope; R. Tecon and M. Pye for providing assistance with histological studies; many student research assistants, including C. Young, M. Huang, S. Heisey, E. Koivunen, C. Loughran, J. Yoshisato, and C. Islas, for assistance with colonization studies; and R. Bostock, D. Rizzo, and M. Wingfield for project development guidance and manuscript edits.

\section{Literature Cited}

Aegerter, B. J., and Gordon, T. R. 2006. Rates of pitch canker induced seedling mortality among Pinus radiata families varying in levels of genetic resistance to Gibberella circinata (anamorph Fusarium circinatum). For. Ecol. Manage. 235:14-17.

Bacon, C. W., and Yates, I. 2006. Endophytic root colonization by Fusarium species: Histology, plant interactions, and toxicity. Pages 133-152 in: Microbial Root Endophytes. B. J. E. Schulz, C. J. C. Boyle, and T. N. Sieber, eds. Springer-Verlag, Berlin.

Bonello, P., Gordon, T. R., and Storer, A. J. 2001. Systemic induced resistance in Monterey pine. For. Pathol. 31:99-106.

Covert, S. F., Kapoor, P., Lee, M. H., Briley, A., and Nairn, C. J. 2001. Agrobacterium tumefaciens-mediated transformation of Fusarium circinatum. Mycol. Res. 105:259-264.

Dwinell, L. D., Barrows-Broaddus, J. B., and Kuhlman, E. G. 1985. Pitch Canker-A disease complex of southern pines. Plant Dis. 69:270-276.

Gordon, T. R. 2006. Pitch canker disease of pines. Phytopathology 96:657-659.

Gordon, T. R. 2011. Biology and management of Gibberella circinata, the cause of pitch canker in pines. Pages 195-208 in: Control of Fusarium Diseases. F. M. Alves-Santos and J. Diez, eds. Research Signpost, Kerala, India.

Gordon, T. R. 2013. Pitch Canker. Pages 376-391 in: Infectious Forest Diseases P. Gonthier and G. Nicolotti, eds. CAB International, Wallingford, UK

Gordon, T. R., Kirkpatrick, S. C., Aegerter, B. J., Fisher, A. J., Storer, A. J., and Wood, D. L. 2011. Evidence for the occurrence of induced resistance to pitch canker, caused by Gibberella circinata (anamorph Fusarium circinatum), in populations of Pinus radiata. For. Pathol. 41:227-232.

Griffin, D. H. 1994. Fungal Physiology, 2nd ed. Wiley-Liss, New York.

Kuldau, G. A., and Yates, I. E. 2000. Evidence for Fusarium endophytes in cultivated and wild plants. Pages $85-120$ in: Microbial Endophytes. C. W. Bacon and J. F. White, eds. Marcel Dekker, Inc., New York.

Leslie, J. F., Summerell, B. A., and Bullock, S. 2006. The Fusarium Lab Manual. Blackwell, Ames, IA.

Lopez-Zamora, I., Bliss, C., Jokela, E. J., Comerford, N. B., Grunwald, S., Barnard, E., and Vasquez, G. M. 2007. Spatial relationships between nitrogen status and pitch canker disease in slash pine planted adjacent to a poultry operation. Environ. Pollut. 147:101-111.

Martín-Rodrigues, N., Sanchez-Zabala, J., Salcedo, I., Majada, J., González-Murua, C., and Duñabeitia, M. K. 2015. New insights into Radiata pine seedling root infection by Fusarium circinatum. Plant Pathol. DOI: 10.1111/ppa.12376

McRoberts, N., Hughes, G., and Madden, L. V. 2003. The theoretical basis and practical application of relationships between different disease intensity measurements in plants. Ann. Appl. Biol. 142:191-211.

Mitchell, R. G., Steenkamp, E. T., Coutinho, T. A., and Wingfield, M. J. 2011. The pitch canker fungus, Fusarium circinatum: Implications for South African forestry. South. For. 73:1-13.

Mitchell, R. G., Zwolinski, J., Jones, N., and Coutinho, T. 2004. The effect of applying prophylactic measures on the post-planting survival of Pinus patula in South Africa. South. Afr. For. J. 200:51-58.

Morris, A. 2010. A review of pitch canker fungus (Fusarium circinatum) as it relates to plantation forestry in South Africa. In: Forest Research. Shaw Research Centre. Sappi

Shah, D. A., and Madden, L. V. 2004. Nonparametric analysis of ordinal data in designed factorial experiments. Phytopathology 94:33-43.

Stergiopoulos, I., and Gordon, T. R. 2014. Cryptic fungal infections: The hidden agenda of plant pathogens. Front. Plant Sci. 5:506.

Storer, A. J., Bonello, P., Gordon, T. R., and Wood, D. L. 1999. Evidence of resistance to the pitch canker pathogen (Fusarium circinatum) in native stands of Monterey pine (Pinus radiata). For. Sci. 45:500-505.

Storer, A. J., Gordon, T. R., and Clark, S. L. 1998. Association of the pitch canker fungus, Fusarium subglutinans f. sp. pini, with Monterey pine seeds and seedlings in California. Plant Pathol. 47:649-656.

Swett, C., Porter, B., Fourie, G., Steenkamp, E. T., Gordon, T. R., and Wingfield, M. J. 2014. Association of the pitch canker pathogen Fusarium circinatum with grass hosts in commercial pine production areas of South Africa. South. For. 76:161-166.

Swett, C. L., and Gordon, T. R. 2011. The cryptic dimension of host-pathogen interactions: Physiological impacts of Fusarium circinatum infection on symptomless Pinus radiata. (Abstr.) Phytopathology 101:S174.

Swett, C. L., and Gordon, T. R. 2012. First report of grass species (Poaceae) as naturally occurring hosts of the pine pathogen Gibberella circinata. Plant Dis. 96:908-908.

Swett, C. L., and Gordon, T. R. 2014. Shoot infection biology of Fusarium circinatum: Wound-free infection and symptomless colonization. (Abstr.) Phytopathology 104:S3.116.

Swett, C. L., and Gordon, T. R. 2015. Endophytic association of the pine pathogen Fusarium circinatum with corn (Zea mays). Fungal Ecol. 13:120-129.

Viljoen, A., Wingfield, M. J., and Marasas, W. F. O. 1994. 1st Report of Fusariumsubglutinans f. sp. pini on pine-seedlings in South-Africa. Plant Dis. 78:309-312.

Wingfield, M. J., Hammerbacher, A., Ganley, R. J., Steenkamp, E. T., Gordon, T. R., Wingfield, B. D., and Coutinho, T. A. 2008. Pitch canker caused by Fusarium circinatum - a growing threat to pine plantations and forests worldwide. Australas. Plant Pathol. 37:319-334. 